\title{
Políticas para mitigação da emissão de gases de efeito estufa: propostas para o Estado de Minas Gerais
}

\section{Lucas Paes Katsuda Ito' ${ }^{1}$, Marco Paulo Vianna Franco ${ }^{2}$}

${ }^{1}$ Fundação João Pinheiro. Escola de Governo. Alameda das Acácias, 70. São Luiz/Pampulha. Belo Horizonte-MG. Brasil. (CEP 31275-150).

${ }^{2}$ Fundação João Pinheiro. Centro de Estatística e Informações. Alameda das Acácias, 70. São Luiz/Pampulha. Belo Horizonte-MG. Brasil. (CEP 31275-150). E-mail: mpvianna@gmail.com.

Resumo. Este trabalho tem por objetivo analisar as políticas públicas para a redução das emissões de gases que provocam o efeito estufa, de maneira a controlar o aquecimento global. São apresentadas teorias e políticas públicas relacionadas ao tema, incluindo instrumentos regulatórios de mercado e de comando e controle. Sob a ótica dessas teorias, são apresentados alguns casos internacionais de aplicação dessas políticas, bem como seus resultados, quando mensurados. Com base nesses conhecimentos, foi analisada a aplicabilidade dessas políticas no Estado de Minas Gerais segundo critérios econômicos, culturais, produtivos, geográficos, financeiros, legais e políticos. Por fim, são sugeridas algumas políticas públicas eficazes na redução das emissões de gases de efeito estufa e condizentes com a realidade de Minas Gerais.

Palavras-chave: Políticas ambientais; Mudanças climáticas; Instrumentos regulatórios; Minas Gerais.

\begin{abstract}
Policies for greenhouse gas emissions mitigation: proposals for the State of Minas Gerais. This work aims to analyze public policies for the reduction of greenhouse gas (GHG) emissions in order to control global warming. For this end, theories and public policies related to the issue are presented, including regulatory market and command/control instruments. From the perspective of these theories, international cases of application of such theories are presented, as well as their results, if measured. Based on this body of knowledge, the applicability of these policies in the state of Minas Gerais is analyzed according to economic, cultural, productive, geographic, financial, legal and political criteria. Finally, public policies that are effective in the reduction of GHG emissions and adequate to the reality of Minas Gerais are suggested for implementation.
\end{abstract}

Keywords: Environmental policies; Climate change; Regulatory instruments; Minas Gerais.
Recebido: $08 / 01 / 2018$

Aceito:

$19 / 04 / 2018$

Publicado: $30 / 04 / 2018$

Acesso aberto

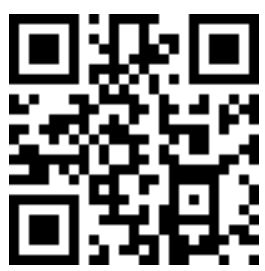

ORCID

(ㄷ) 0000-0003-1720-642X Lucas Paes Katsuda Ito

D 0000-0002-0054-8717

Marco Paulo Vianna

Franco 


\section{Introdução}

Segundo o Instituto Nacional de Pesquisas Espaciais (INPE, 2011, p. 1), além do aumento dos níveis dos oceanos, o agravamento do aquecimento global:

[...] tem impactos profundos no planeta: extinção de espécies animais e vegetais, alteração na frequência e intensidade de chuvas (interferindo, por exemplo, na agricultura), elevação do nível do mar e intensificação de fenômenos meteorológicos (por exemplo: tempestades severas, inundações, vendavais, ondas de calor, secas prolongadas), entre outros.

Assim, a não reversão dessa tendência comprometeria a base econômica, a manutenção do capital natural e a promoção da justiça social, uma vez que agravariam as condições de vulnerabilidade a que estão sujeitos boa parte da população e grande porção dos ecossistemas. 0 aumento da temperatura impactaria setores vitais para as economias, tais como a oferta de recursos hídricos, a geração de energia, a produtividade dos campos agrícolas, além da estabilidade das cidades costeiras, nas quais se encontram a maior parte das populações dos países. Vale ressaltar que tais impactos seriam mais intensos nos países em desenvolvimento, uma vez que são mais vulneráveis devido à menor capacidade tecnológica e financeira de resposta e adaptação às consequências da alteração da temperatura (Comissão Mista Permanente sobre Mudanças Climáticas [CMMC], 2013). Ainda, em relação ao cenário brasileiro, os maiores prejuízos socioambientais e econômicos das alterações ambientais seriam:

o agravamento da escassez de oferta hídrica no Nordeste semiárido; na Amazônia: perda de biodiversidade (extinção de espécies), substituição de florestas tropicais por savanas, desertificação e salinização de terras agriculturáveis. 0 cenário de substituição de áreas florestais na Amazônia envolveria ainda a alteração do regime de chuvas nas regiões de produção agrícola situadas no Centro-Sul do País; e por fim, o aumento do nível do mar, com prejuízos às cidades costeiras. (CMMC, 2013, p. 8).

Já para o Estado de Minas Gerais, segundo a Fundação Estadual do Meio Ambiente (FEAM, 2015), é esperado um aumento de temperatura que, de forma conservadora, poderia alcançar de $2{ }^{\circ} \mathrm{C}$ a $4^{\circ} \mathrm{C}$ e, em cenários mais pessimistas, de $3{ }^{\circ} \mathrm{C}$ a $5^{\circ} \mathrm{C}$, até 2100 . Além disso:

[...] estima-se que desde 2008, eventos climáticos extremos como chuvas intensas e secas prolongadas tenham custado 12,8 bilhões de reais ao estado. Caso nada seja feito, os custos dos impactos para a economia mineira decorrentes das mudanças climáticas podem alcançar $\mathrm{R} \$ 450$ bilhões até 2050. (FEAM, 2015, p. 9).

Diante dessas consequências, esforços oriundos de organismos internacionais e de governos em nível federal, estadual e municipal estão sendo feitos com a finalidade de mitigar e adaptar as localidades a essa variação climática. Embora as emissões sejam locais, seus efeitos são difusos. Assim, é necessária a intervenção e a criação de organismos internacionais para tratarem do assunto. Diante disso, organismos internacionais como a Organização das Nações Unidas (ONU) passaram a mobilizar grande parte dos países com o intuito de firmarem acordos que visem produzir mais informações a respeito do aquecimento global e controlar as emissões através de políticas públicas locais. Para tanto, definiram-se metas que deveriam ser respeitadas e seguidas por todos os países signatários.

A Lei no 12.187/2009, de iniciativa do Governo Federal, instituiu a Política Nacional sobre Mudança do Clima (PNMC), obrigando os estados a 
legislarem sobre essa área. As diretrizes da PNMC estimulam e apoiam a participação dos governos estaduais, municipais e do Distrito Federal, compartilhando essa atribuição entre os entes nacionais, por meio da criação de suas políticas estaduais e municipais de mudanças climáticas. Em 2012, 17 estados brasileiros já possuíam lei sancionada ou projeto de lei para regulamentar a política estadual de mudanças climáticas. Este aparato define estruturas de governança, planos e instrumentos para a consecução dos seus objetivos.

Em Minas Gerais, o meio ambiente começou a fazer parte da agenda política e da legislação de forma direta em 2003, com a criação do Núcleo de Gestão Ambiental (NGA), "com a finalidade de promover a gestão transversal e a análise da variável ambiental na elaboração e execução dos planos, programas e projetos, bem como promover a articulação e parceria efetiva entre órgãos e entidades do Estado no que diz respeito à temática ambiental" (Decreto no 43.372/2003). Em 2005, foi criado o Fórum Mineiro de Mudanças Climáticas Globais, pelo Decreto $\mathrm{n}$ ㅇ $44.042 / 2005$, que marcou efetivamente a entrada do tema na agenda governamental, promovendo discussões sobre o fenômeno global e a necessidade de políticas públicas a serem desenvolvidas, aplicadas e implantadas. Como fruto dessas iniciativas, em 2008 foi apresentado pioneiramente no estado o Inventário de Emissões de Gases de Efeito Estufa do Estado de Minas Gerais, ano base 2005, que objetivava identificar o nível de emissões de gases estufa e suas principais fontes (Fundação Estadual do Meio Ambiente e Centro Clima - Universidade Federal do Rio de Janeiro, 2008). No ano seguinte, entrou em vigor o Decreto no 45.229/2009, que criou o Programa de Registro Público Voluntário das Emissões Anuais de Gases de Efeito Estufa do Estado. Tal programa foi uma importante iniciativa governamental que buscava reconhecer, encorajar e promover ações para a gestão voluntária de emissões de gases de efeito estufa, além de regulamentar a ação da própria administração pública direta e indireta em relação à frota de carros comprados, alugados e 0 combustível utilizado por esses. Em 2012, buscando reforçar o compromisso do estado mineiro no combate às mudanças climáticas, incluiu-se na principal ferramenta de planejamento do Estado, o Plano Plurianual de Ação Governamental (PPAG) 2012-2015, a elaboração de planos setoriais de mitigação e adaptação às mudanças climáticas e a realização de cenários tendenciais de emissões. Por fim, em 2015, o Decreto no 46.818/2015 criou o Comitê Político do Plano de Energia e Mudanças Climáticas de Minas Gerais (PEMC-MG), com caráter deliberativo, tendo como finalidade acompanhar as revisões periódicas de aperfeiçoamento e a implantação das ações setoriais e transversais do PEMC-MG.

Entretanto, ainda são ínfimos os resultados obtidos no estado quanto à efetiva redução das emissões de gases efeito estufa (GEE) a partir de políticas públicas não relacionadas ao controle do desmatamento. Assim, faz-se oportuno analisar os diferentes tipos de políticas existentes, buscando identificar ações que possam ser implantadas pelo governo estadual. Para tanto, é necessário conhecer cada um dos tipos de políticas, bem como suas vantagens e limitações, na tentativa de determinar quais seriam as mais adequadas e em quais situações. Tendo isso em vista, há que se compreenderem fatores como o tipo de falha de mercado em ação, a natureza do problema ambiental a ser mitigado, o grau de incerteza em relação ao custo-benefício das políticas, preocupações quanto à competitividade do mercado e questões de monitoramento e fiscalização, entre outros. Apenas após ser traçado o perfil da localidade sob análise seria possível a escolha da política mais adequada dentre os diferentes modelos disponíveis. 
0 presente trabalho, portanto, tem como objetivo caracterizar e sugerir diferentes tipos de políticas públicas que poderiam ser adotadas para a redução das emissões de GEE em Minas Gerais, tendo em vista as particularidades do Estado.

\section{Referencial teórico}

\section{Teorias da Regulação}

Do ponto de vista econômico, a regulação incide sobre as falhas de mercado, principalmente nas áreas de interesse público, a fim de preservar e promover direitos fundamentais, como o acesso a serviços essenciais e a proteção da saúde e da vida. Nos termos de Posner (1974, p. 335), "regulação econômica é a expressão que se refere a todos os tipos de impostos e subsídios, bem como os controles legislativos e administrativos explícitos sobre taxas, ingresso no mercado e outras facetas da atividade econômica". Basicamente, a regulação visa corrigir falhas de mercado, como a concorrência imperfeita, assimetrias de informação e externalidades (que surgem quando os agentes tomam decisões baseadas apenas nos benefícios e custos privados, e não sociais), direcionando a conduta dos agentes de maneira a maximizar o bem-estar econômico e social.

As duas abordagens mais comuns acerca da regulação econômica do Estado são a Teoria do Interesse Público e a Teoria Econômica da Regulação. A primeira consiste em uma teoria normativa da regulação, que define as condições e os princípios da intervenção sobre a economia. Os agentes reguladores diminuiriam as ineficiências geradas pelas falhas de mercado, contribuindo para a maximização do bem estar social com base nas demandas da sociedade (Campos, 2008).

A Teoria Econômica da Regulação, por sua vez, procura explicar como o processo regulatório se organiza e gera resultados diante das ações dos agentes. Ela destaca a distância entre os objetivos almejados e as ações dos entes regulatórios, muitas vezes motivados por interesses próprios, contrários ao interesse público. Baseada na ideia de que de que haveria uma captura do regulador pelo regulado (conhecida como Teoria da Captura), essa vertente caracteriza a regulação como uma demanda da própria indústria regulada, ofertada pelos legisladores em troca de capital político ou financeiro, em detrimento do interesse público (Posner, 1974).

\section{Modelos de Políticas Públicas}

Theodore Lowi (1964, 1972), em sua Abordagem das Arenas, distingue quatro tipos de políticas públicas. 0 primeiro tipo é composto por políticas distributivas, as quais consistem na distribuição de recursos provenientes da coletividade a frações específicas da sociedade, de acordo com a categoria das pessoas, localidades, regiões e grupos sociais. As políticas redistributivas formam o segundo tipo, sendo aquelas que realocam bens ou serviços a segmentos particularizados da população por intermédio de recursos oriundos de outros grupos específicos. Estas se diferenciam das políticas distributivas na medida em que têm como fonte financiadora certo grupo da população não beneficiado pela política. Existem também as políticas constitutivas ou estruturadoras, que consistem nas normas e procedimentos sobre os quais devem ser formuladas as demais políticas públicas. Finalmente, as políticas regulatórias estabelecem obrigatoriedades, interdições e condições, por meio das quais devem ser realizadas determinadas atividades ou admitidos certos comportamentos. Os custos e benefícios destas últimas podem ser disseminados equilibradamente ou podem privilegiar interesses restritos, assim como podem variar de regulamentações simples e operacionais a regulações complexas, de grande abrangência (Rua e Romanini, 2011). 
0 presente trabalho tem como foco as políticas distributivas e regulatórias. Dentro desses dois tipos, há diversos instrumentos com diferentes características e efetividades. Em se tratando de problemas de poluição industrial e urbana, esses instrumentos podem ser divididos em dois tipos principais: instrumentos de comando e controle e instrumentos de mercado.

Instrumentos de comando e controle têm sido a base de sistemas de gestão do meio ambiente em países industrializados com legislação ambiental consolidada. Tal modelo consiste num conjunto de normas, regras, procedimentos e padrões a serem obedecidos pelos agentes econômicos para que se adequem a metas ambientais previamente estipuladas. A exequibilidade desse instrumento é garantida pela fiscalização e, caso cabível, a penalização dos agentes, segundo as punições previstas para os infratores. Para que esses instrumentos funcionem com eficácia, é fundamental que o órgão de controle ambiental seja capaz de fazer com que os poluidores se adequem aos padrões ou sofram sanções (Margulis, 1996).

Existem três principais tipos de instrumentos de comando e controle aplicados à gestão ambiental: licenças ambientais, zoneamento e padrões. Os padrões, instrumentos frequentemente empregados na gestão ambiental, consistem na imposição de limites ou tecnologias que, com base em estudos prévios, auxiliem na redução das emissões em um determinado processo produtivo. Segundo Margulis (1996), os padrões podem ser aplicados a parâmetros como qualidade ambiental (limites máximos de concentração de poluentes no meio ambiente), emissões (limites máximos para as concentrações ou quantidades totais a serem despejadas no ambiente por uma fonte de poluição), tecnologia (determinam o uso de tecnologias específicas) e desempenho (especificam, por exemplo, a eficiência de um determinado processo), entre outros.

Uma limitação dos instrumentos de comando e controle diz respeito à sua baixa flexibilidade para atender casos diferentes de formas diferentes. Tais instrumentos não levam em consta os efeitos econômicos ou os custos em que as indústrias incorrem ao se enquadrar dentro dos limites ou ao adotar a tecnologia imposta:
a adoção de um determinado padrão tecnológico, por exemplo, pode trazer eficiência mas também conspirar contra a viabilidade econômica de produtores menores, criando assim um problema de distribuição. Também pode aumentar os custos de produção de empresas situadas em localidades isoladas, onde a poluição não seja um problema. E isto anula os incentivos para que as empresas poluidoras se desloquem para áreas menos densamente povoadas, o que é geralmente desejável do ponto de vista ambiental (Margulis, 1996, p. 5).

Contudo, essa é uma característica que pode ser necessária quando os efeitos da poluição controlada são muito danosos ou prejudiciais à coletividade.

Os instrumentos de mercado, por sua vez, são mais maleáveis e levam em consideração fatores econômicos. Por isso, vêm sendo progressivamente mais adotados em vários países do mundo de forma complementar - e não em substituição - aos instrumentos de comando e controle. Eles se baseiam nas forças do mercado, atuando por meio de mudanças dos preços relativos, de maneira a influenciar o comportamento de poluidores e usuários de recursos públicos e privados. Desse modo, diz-se que instrumentos de mercado visam internalizar custos externos, de maneira a incorporar os aspectos ambientais às decisões dos agentes econômicos. A desconsideração dos custos sociais e 
ambientais levaria a uma utilização excessiva dos recursos naturais e, consequentemente, à degradação ambiental. Assim, obrigam-se os poluidores a arcarem com os custos necessários para que se atinjam níveis de poluição que maximizem o bem-estar social. Nesse sentido, instrumentos de mercado são mais eficientes ao minimizarem os custos totais; geram incentivos permanentes para a busca de tecnologias mais limpas e mais baratas; consistem em uma fonte adicional de recursos para os governos financiarem programas ambientais; conferem às indústrias mais flexibilidade e autonomia no controle de suas emissões; e necessitam de menos informações sobre as empresas por parte dos órgãos de controle ambiental (Margulis, 1996). Exemplos desses instrumentos seriam as taxas ambientais (por emissão ou por produto, diferenciadas ou não), a criação de mercados de poluição (créditos de carbono), subsídios e sistemas de depósito e reembolso (praticado na reciclagem de produtos).

Além dos instrumentos de comando e controle e de mercado, os órgãos ambientais vêm utilizando outros meios e iniciativas para regular a ação de agentes poluidores. Entre os principais, destacam-se políticas de educação e conscientização, que visam reduzir as assimetrias de informação quanto aos reais efeitos das atividades produtivas sobre o meio ambiente, induzindo assim a elaboração de políticas públicas mais assertivas e participativas, hábitos de consumo mais ecologicamente sustentáveis e a negociação direta ou acordos voluntários entre poder público e agentes econômicos (Margulis, 1996).

Diante de todo esse rol de instrumentos e políticas existentes para a mitigação da emissão de GEE, cabe ao gestor escolher qual delas seria a mais adequada para cada situação. Segundo Margulis (1996), a decisão pode ser baseada em critérios ecológicos (extensão dos impactos físicos, irreversibilidade ou a recorrência dos problemas), sociais (número de pessoas afetadas, os efeitos nocivos à saúde, incidência sobre os mais pobres) e econômicos (efeitos sobre a produtividade e o crescimento econômico). A escolha da política a ser utilizada seria resultado do debate político entre comunidades afetadas, poluidores, especialistas em meio ambiente, terceiro setor e órgãos governamentais. Assim, para que a escolha da política a ser adotada seja a mais acertada possível, é importante que os envolvidos estejam familiarizados com os instrumentos disponíveis e aptos a avaliar sua viabilidade técnica, administrativa e financeira.

\section{Procedimentos metodológicos}

A metodologia do trabalho baseou-se em extensa pesquisa documental, incluindo legislações internacionais, nacionais e estaduais, tratados internacionais e fontes secundárias, para que fosse possível atingir o objetivo de elencar um rol de propostas de políticas públicas de mitigação da emissão de GEE aplicáveis ao Estado de Minas Gerais, a partir de experiências internacionais de sucesso. Foram selecionados para análise os setores que apresentam maior representatividade no montante de emissões em Minas Gerais de acordo com FEAM (2015). O processo de escolha de experiências de sucesso foi direcionado a países considerados referência na mitigação de emissões de GEE nos setores em foco, contando com legislação pioneira no tema ou resultados notórios segundo organismos internacionais ou fontes governamentais. Nos casos em que não foi possível atender a tais critérios, optou-se por incluir na análise localidades que apresentam produção significativa no respectivo setor e que dispõem de regulamentação com vistas à redução da emissão de GEE. 


\section{0 recorte setorial}

Os dados utilizados para a delimitação do recorte setorial estão disponíveis em FEAM (2013). Esse relatório calcula as emissões por setores e subsetores socioeconômicos dos gases dióxido de carbono, metano, óxido nitroso, tetrafluoroetano e hexafluoroetano, em $\mathrm{Gg} \quad \mathrm{CO}_{2} \mathrm{e}$ (gigagramas ou mil toneladas de dióxido de carbono equivalente).

Para o cálculo do potencial de redução de emissão em cada um dos setores, FEAM (2015) leva em consideração apenas as diminuições resultantes das ações propostas pelo próprio plano. Dessa forma, o potencial de redução pode variar de acordo com a execução dessas ações, bem como a realização de novas políticas públicas. Contudo, tais parâmetros constituem boa aproximação para a seleção do recorte setorial.

A metodologia usada por FEAM (2015) para dividir as emissões por setores de acordo com seu potencial de redução de emissões optou por agrupar os setores "Mudança de Uso do Solo" e "Agropecuária". Devido a isso, para facilitar a análise desses potenciais e, consequentemente, avaliar políticas públicas de forma individualizada, classificaram-se as ações "Programa estadual de recuperação de pastagens degradadas" e "Melhoramento genético e redução das emissões de metano dos ruminantes" como pertencentes ao setor "Agropecuária". As ações "Apoio e incentivo à produção e uso sustentável de florestas plantadas", "Revisão e ampliação do Plano Estadual de Fomento Florestal" e "Estratégia integrada de prevenção e combate ao desmatamento no território mineiro" foram classificadas como parte do setor "Mudança de Uso do Solo". Tal divisão foi feita de acordo com o objeto da ação: quando atuante na área de agricultura e pecuária, a mesma foi classificada como pertencente ao setor "Agropecuária"; se agir sobre o desmatamento ou plantação de florestas, como parte do setor "Mudança de Uso do Solo".

FEAM (2013) indica uma emissão total de 123.434,3 $\mathrm{Gg} \mathrm{CO}_{2} \mathrm{e}$ no ano de 2010 para todos os setores do estado de Minas Gerais, 0,6\% a menos do que as estimativas do último relatório realizado em 2005, o que representa uma estabilização das emissões no Estado, mesmo com o crescimento econômico constatado no período (aproximadamente 25\% de crescimento entre 2005 e 2010, segundo dados da Fundação João Pinheiro [2012]). Tal manutenção do nível de emissões é decorrente, principalmente, da grande redução do desmatamento e das emissões dele provenientes, que no período observado reduziu $82 \%$, totalizando em números brutos uma diminuição de $13.742,7 \mathrm{Gg} \mathrm{CO}_{2} \mathrm{e}$.

Setor agropecuário. 0 setor agropecuário, no ano de 2010, representou 39,3\%, (48.551,2 $\mathrm{Gg} \mathrm{CO}_{2} \mathrm{e}$ ) do total de emissões, sendo $60,6 \%$ deste valor proveniente da pecuária e 39,4\% da agricultura. Segundo FEAM (2015), o potencial de redução do setor balizado pelas ações escolhidas é de 78.912,8 Gg $\mathrm{CO}_{2} \mathrm{e}$ até 2030. As emissões desse setor são oriundas principalmente do processo de fermentação entérica do gado, manejo de dejetos animais, solos agrícolas, calagem, cultivo de arroz e queima de resíduos agrícolas. Tamanho montante pode ser explicado pela grande relevância da atividade agropecuária na economia mineira, com destaque para os rebanhos de bovinos e suínos. O setor é dividido nos subsetores "Pecuária" e "Agricultura".

Setor de energia. 0 setor energético foi responsável por 44.401,0 $\mathrm{Gg} \mathrm{CO}_{2} \mathrm{e}$, ou $36 \%$ das emissões mineiras no ano de 2010. De acordo com FEAM (2015), o potencial de redução balizado pelas ações escolhidas do presente setor é de 5.679,3 $\mathrm{Gg} \mathrm{CO} \mathrm{CO}_{2} \mathrm{e}$ até 2030. Nesse setor, as emissões são decorrentes da queima de combustíveis fósseis $\mathrm{e}$ 
biomassa na produção, transformação e consumo de energia, bem como as emissões fugitivas decorrentes do refino, transporte e distribuição do petróleo e gás natural. 0 subsetor que mais emitiu GEE em 2010 foi o de "Transporte", com $47,3 \%$ do total, seguido pelo subsetor "Indústria", com 38,6\% das emissões. Em relação à participação dos combustíveis como fontes de emissão, os consumos de óleo diesel e gasolina apresentaram as maiores emissões de GEE, respectivamente com $36,9 \%$ e $13,9 \%$ das emissões do setor. No subsetor "Transporte", o modal rodoviário foi responsável por $94,5 \%$ das emissões devido ao consumo de combustíveis, com o óleo diesel representando $67,1 \%$ do total e a gasolina $29,4 \%$.

\section{Setor de processos industriais.} 0 setor "Processos Industriais" representou $15,8 \%$ do total de emissões em Minas Gerais, ou 19.467,0 Gg CO C $_{2}$ de GEE. Segundo FEAM (2015), o potencial de redução do setor balizado pelas ações escolhidas é de $3.411,5 \mathrm{Gg} \mathrm{CO}_{2} \mathrm{e}$ até 2030. As emissões que compõem tal setor são resultantes dos processos produtivos das indústrias, excluindo-se as resultantes da queima de combustíveis. 0 subsetor mais representativo foi o de "Minerais Metálicos", que inclui a siderurgia e a produção de alumínio, responsável por $53,2 \%$ do total. Os subsetores "Minerais Não Metálicos" e "Indústria Química" contribuíram, respectivamente, com $46,7 \%$ e $0,07 \%$ do total de emissões.

Demais setores. Os montantes de emissões referentes aos setores "Mudança de Uso do Solo" e "Tratamento de Resíduos" representam, respectivamente, $2,5 \%$ e $6,4 \%$ e, juntos, totalizam 11.015,2 $\mathrm{Gg} \mathrm{CO}_{2} \mathrm{e}$ ou 8,9\% do total de emissões de GEE. Segundo FEAM (2015), o potencial combinado de redução desses setores, balizado pelas ações escolhidas, é de 84.243,4 $\mathrm{Gg} \mathrm{CO}_{2} \mathrm{e}$ até 2030. As emissões e remoções contabilizadas no setor "Mudança de Uso do Solo" são resultantes das variações da quantidade de carbono, seja da biomassa aérea, seja do solo, considerando-se as transições possíveis entre os diversos usos. A remoção de $\mathrm{CO}_{2}$ é resultante do crescimento da vegetação de porte florestal em áreas consideradas manejadas. Já as emissões que compõem o "Tratamento de Resíduos" são resultantes da disposição e tratamento de resíduos, incluindo compostagem, incineração e tratamento de efluentes domésticos e industriais.

O setor "Mudança de Uso do Solo" é o maior responsável pelo batimento da meta estipulada pelo Brasil na COP 21 (21a sessão anual da Conferência das Partes da Convenção-Quadro das Nações Unidas sobre as Alterações Climáticas), que estabeleceu a redução da emissão de GEE em $37 \%$ até 2025 e $43 \%$ até 2030 , tendo como referência as emissões de 2005. Grande parte dessa meta já foi cumprida pela redução do desmatamento da floresta Amazônica, que apresentou uma redução agregada maior do que $70 \%$ desde 2004 , apesar de uma queda da redução do desmatamento em 2016 (Azevedo et al., 2016). Esse cenário se repete em Minas Gerais, onde a queda das taxas de desmatamento contribuiu para a redução das emissões nos últimos anos. Entretanto, as reduções provenientes desse setor estão próximas do seu limite de contribuição, dado que não haveria mais ganhos ao se atingir o "desmatamento zero", além do fato de que tais reduções ocorrem a taxas decrescentes. Assim, o montante de emissões provenientes do setor "Mudança de Uso do Solo", atualmente pequeno, não foi analisado neste trabalho. Porém, vale ressaltar que a manutenção das baixas taxas de desmatamento é de grande relevância para o sucesso das políticas de mitigação de emissões de GEE.

\section{0 recorte adotado}

Os setores escolhidos para análise foram a "Agropecuária" e "Energia", responsáveis respectivamente por $39,3 \%$ e $36 \%$ do total de emissões. 
Foram ainda selecionados, dentre tais setores, os subsetores que se destacaram em termos da representatividade nos percentuais de emissões, a saber: "Agricultura" e "Pecuária", no setor agropecuário, e "Transporte" e "Indústria", no setor energético. Para o subsetor "Indústria", devido à grande variedade de indústrias que o compõem, optou-se por restringir a análise a dois ramos que apresentaram os maiores montantes dentro do subsetor: o siderúrgico e o cimenteiro. Esses setores, em conjunto, são responsáveis pela emissão de $75,3 \%$ de todas as emissões mineiras no período.

Por fim, ressalta-se que fogem ao escopo do trabalho políticas de adaptação às mudanças climáticas, que são aquelas realizadas com o objetivo de modificar as estruturas urbanas de maneira a torná-las mais adequadas aos efeitos dessas mudanças. Além disso, leis e políticas circunscritas ao setor público foram preteridas em relação àquelas destinadas à sociedade como um todo, dado o maior alcance destas últimas.

\section{Resultados e discussão}

\section{Experiências internacionais de políticas públicas de mitigação de GEE}

Subsetor "agricultura". Segundo

a World Trade Organization (2016), a União Europeia é a maior exportadora em valores de produtos agrícolas, sendo o setor agrícola responsável por $10 \%$ do total de emissões da União Europeia. Devido à grande relevância desse setor para a economia europeia, foi criada a Política Agrícola Comum da União Europeia (Union's Common Agricultural Policy - CAP), que destina subsídios e incentivos para o desenvolvimento rural. Em 2013, houve uma tentativa de reestruturação dessa política, de forma a considerar algumas diretrizes que visem também à redução da emissão de GEE, dado que, de acordo com Gattinger et al. (2011), as emissões no setor deverão compor cerca de um terço das emissões de GEE da União Europeia em 2050. A ideia básica se referia à complementação da CAP, com a inclusão de critérios de financiamento sustentáveis, como a utilização de certas práticas agrícolas ou de fertilizantes menos poluentes. Dessa forma, o governo, por meio de suas instituições financeiras, conseguiria conduzir a utilização de insumos e a adoção de práticas mais sustentáveis, ao impô-las como pré-requisito para o acesso às linhas de financiamento previstas na CAP. Tais políticas seriam capazes de integrar objetivos econômicos e finalidades ambientais, gerando demanda por produtos e processos menos emissores e, consequentemente, reduzindo os custos via avanços tecnológicos e economias de escala.

De maneira complementar, destacam-se as políticas agrícolas de mitigação da emissão de GEE adotadas na Indonésia, focadas na produção de arroz. 0 país, grande produtor e consumidor desse cereal, vem sendo fortemente afetado por desastres naturais que podem estar diretamente ligados ao aquecimento global. Levando isso em conta, o governo criou políticas baseadas em diversos tipos de instrumentos: (i) de informação e educação, que consistiram na elaboração de estudos para a diversificação da agricultura indonésia, buscando alternativas menos poluentes em relação à produção de arroz; (ii) de mercado, baseados na criação de fundos para o financiamento de ações como subsídios para fertilizantes, pesticidas e sementes que levem a uma menor emissão de GEE; e (iii) de comando e controle, por meio da proibição de práticas incendiárias como método de limpeza do solo.

Subsetor "pecuária". Para a análise da pecuária, foram utilizados os casos do Sul Asiático (China e Índia) e da América do Sul, regiões que incluem muitos dos países com as maiores produções de leite e carne do mundo.

Para o Sul Asiático, Gerber et al. (2013) propuseram políticas de redução 
das emissões de GEE a partir de características comuns à Índia e China. Estas estão ligadas à baixa produtividade dos rebanhos em relação à quantidade de emissões, resultado de fatores como a alta mortalidade de animais e alimentação de difícil digestão. Por outro lado, os autores destacam aspectos positivos do manejo produtivo nesses países, onde $28 \%$ das criações são mistas, ou seja, produzem carne e leite, em comparação com proporções menores do que $10 \%$ para a União Europeia ou Estados Unidos, por exemplo. Diante disso, foram propostas duas políticas: a melhoria da composição do alimento dados às vacas, que além de reduzir a produção do gás metano pelo processo de fermentação entérica dos animais, resultaria em maiores produções de leite e carne por unidade de emissões; e o aperfeiçoamento das técnicas de reprodução e manutenção da saúde dos bovinos, que também elevariam a produção sem aumentos correspondentes nas emissões. Segundo os autores, tais mudanças implicariam numa redução de $38 \%$ das emissões do setor pecuário no Sul Asiático, sendo $30,4 \%$ resultantes da melhora da qualidade alimentícia e 7,6\% decorrente da melhora da saúde e das técnicas de reprodução.

Foram analisadas também propostas e políticas de mitigação para esse subsetor no caso da América do Sul. 0 setor de produção de carne bovina especializada no continente, segundo Gerber et al. (2013), é responsável pela produção de $31 \%$ da produção especializada no mundo, porém com $54 \%$ das emissões da atividade no total mundial, o que revela uma baixa produtividade. Tal ineficiência é resultante tanto da utilização das fezes do gado para adubar o solo, quanto de deficiências no aprimoramento genético dos animais, uma vez que os autores estimam que os bovinos sul-americanos têm taxas de crescimento $25 \%$ menores quando comparados à média mundial.
Alicerçados nesses dados, Gerber et al. (2013) indicaram algumas políticas baseadas na melhora da qualidade e gestão do pasto e na melhora da saúde e qualidade de vida dos bovinos. Tais ações auxiliariam no processo digestivo dos animais, que cresceriam e se reproduziriam mais rapidamente, além de atingirem o porte de corte de forma antecipada. Ações preventivas como a vacinação e o fornecimento de água limpa e sombra são exemplos na consecução desses objetivos. Os autores preveem que essas políticas seriam capazes de reduzir de $18 \%$ a $29 \%$ as emissões de GEE no subsetor. A combinação de taxas mais elevadas de crescimento e fertilidade com menores taxas de mortalidade reduziria o número de fêmeas mantidas para a reprodução em $44 \%$ e, em consequência disso, a porcentagem de fêmeas para abatimento aumentaria de $49 \%$ para $65 \%$. Para a implantação das práticas sugeridas, seriam indicados padrões ou instrumentos de mercado, como a taxação diferenciada de produções que emitam menos GEE, assim como políticas de educação e conscientização, buscando a adesão voluntária dos pecuaristas a técnicas mais adequadas de manejo do rebanho, justificada pelos ganhos econômicos proporcionados aos próprios produtores.

Subsetor "transporte". A grande representatividade das emissões desse setor em relação ao total de emissões em Minas Gerais é decorrente da preponderância do modal rodoviário para o transporte de cargas e de pessoas, com combustíveis fósseis como principal insumo. 0 caso dinamarquês foi então adotado como experiência de sucesso aplicável a esse subsetor em Minas Gerais.

Há dois grandes marcos das políticas de mitigação da emissão de GEE na Dinamarca. Primeiramente, em 2008, a eficiência dos meios de transporte passou a ser foco do governo, remodelando a legislação vigente $\mathrm{e}$ 
alterando a alocação de recursos. 0 segundo marco ocorreu no ano de 2012, quando o governo definiu que, até 2050 , todas as fontes de energia do país fossem provenientes de fontes renováveis (Mathiesen e Kappel, 2013). Foram analisados no trabalho três grupos de políticas voltadas ao subsetor "Transporte": aquelas relacionadas ao planejamento urbano, as baseadas em impostos para veículos e outras mais especificamente ligadas ao modal rodoviário.

As políticas de planejamento urbano foram desenvolvidas de maneira a descentralizar o comércio, serviços e instituições públicas. Dessa forma, foi estimulada a criação de regiões mais independentes e economicamente ativas, tornando menor a necessidade de deslocamentos motorizados e reduzindo as distâncias entre áreas residenciais e comerciais. Outra iniciativa foi a expansão da rede de ciclovias, tornando as bicicletas um meio de transporte cada vez mais conveniente para a população. Em Copenhagen, no ano de 2007, 36\% de todas as viagens foram feitas utilizando bicicletas (Municipality of Copenhagen, 2007). A boa integração entre os modais de transporte público e bicicletas foi outro fator relevante para o sucesso dessa prática, com a adaptação dos ônibus e trens para receberem bicicletas de maneira confortável e gratuita. Tal integração se deve à interligação entre municípios por modais ferroviários e metroviários.

Segundo Mathiesen e Kappel (2013), os investimentos públicos dinamarqueses na área de transporte urbano são direcionados ao transporte público (cerca de 80\%). Foram adotadas ações locais como a redução do preço do transporte público em horários de baixa demanda, preços diferenciados para estudantes, $20 \%$ de aumento da oferta de viagens, eletrificação de rotas e remodelagem do trânsito de forma a privilegiar as "superciclovias", que têm preferência de mobilidade, estando sujeitas a menos semáforos e paradas obrigatórias. As políticas voltadas para o planejamento urbano constituíram, portanto, políticas distributivas, baseadas em instrumentos de mercado, via subsídios, e em instrumentos de comando e controle, impondo restrições ao tráfego de veículos particulares.

O segundo grupo de políticas foi baseado nos impostos veiculares. $\mathrm{Na}$ Dinamarca, há três tipos de impostos para veículos que, juntos, somam um custo de aproximadamente $180 \%$ do valor do automóvel (Mathiesen e Kappel, 2013). São cobrados uma tributação progressiva sobre o registro do veículo, uma taxa "verde" sobre propriedade e um imposto sobre o combustível. A progressividade da tributação sobre o registro do veículo leva em conta seu preço e a eficiência média do modelo do veículo (quilometragem percorrida por litro de combustível). A taxa "verde" sobre propriedade, cobrada anualmente, também varia com a eficiência do modelo do veículo, e pode incluir taxas extras relacionadas a emissões, como no caso de veículos a diesel sem filtros de partículas. 0 imposto sobre 0 combustível, por sua vez, incide sobre o valor do litro de cada tipo de combustível, de acordo com suas emissões específicas. Apesar da ausência de estudos quantitativos de referência (anteriores a 1997) acerca da eficiência energética da frota dinamarquesa, Mathiesen e Kappel (2013) afirmam que a incidência de tais tributos tem sido eficaz ao incentivar a compra de veículos mais eficientes no país. Em 2000, a média de consumo de combustível dos automóveis em circulação era de 7 litros para 100 quilômetros percorridos, valor reduzido para 5,5 litros em 2010. Finalmente, em relação ao transporte rodoviário de cargas, foi criado um novo imposto para caminhões, baseado na quilometragem rodada, com os objetivos de otimizar a utilização da capacidade dos mesmos e de transferir parte das cargas para os modais aquaviário e ferroviário, atualmente subutilizados, segundo Mathiesen e Kappel (2013). 
Todavia, ressalta-se que o aumento da eficiência dos veículos dinamarqueses teve seu impacto positivo sobre as emissões de GEE compensado nos últimos anos pelo aumento do número total de veículos em circulação, resultado do crescimento econômico do país, mesmo com a vigência de uma ampla gama de políticas de estímulo à substituição do transporte privado pelo sistema público de transporte.

\section{Subsetor "indústria"}

Indústria siderúrgica. As emissões de GEE da indústria siderúrgica se devem às características do seu processo produtivo, altamente intensivo em energia. A energia térmica envolve quase todos os processos, sendo mais intensamente utilizada em unidades integradas, as quais englobam os processos de sinterização, coqueificação, redução e refino (Carvalho et al., 2015). Segundo a World Steel Association (2016), a China é o maior produtor de aço do mundo, fabricando 49,6\%, seguido pela União Europeia, responsável pela produção de $13 \%$ de toda a produção mundial. Com o objetivo de mitigar as emissões decorrentes de toda essa produção, a China criou uma política baseada em padrões de emissão de GEE, de desempenho e tecnológico, que delimitam níveis mínimos de eficiência e as tecnologias a serem utilizadas no processo produtivo. Para tanto, são levados em consideração os diferentes tipos de matérias-primas, unidades auxiliares e combustíveis empregados nas plantas siderúrgicas. Dessa forma, a política reduz as emissões de GEE através da orientação da produção em direção a determinadas matérias primas, técnicas e tecnologias mais produtivas (Carvalho et al., 2015).

A União Europeia instituiu um esquema de comércio de emissões (European Union Emissions Trading Scheme) na indústria siderúrgica que limita o montante de emissões a um valor prévio por empresa (denominado modelo cap-and-trade), possibilitando a posterior comercialização das parcelas não emitidas na forma de créditos de carbono, tal como proposto em nível global pelo Protocolo de Quioto (Carvalho et al., 2015). Assim, ao final de cada ano, as empresas apresentam seu inventário de emissões de GEE para o cálculo das emissões. Caso as empresas emitam menos do que o limite estabelecido, terão direito a créditos de carbono, os quais podem ser negociados com outras empresas ou guardados para posterior utilização. Se o limite for ultrapassado, a empresa fica em débito com o sistema, sendo obrigada a quitar essa dívida por meio de créditos de outros exercícios ou comprados de outras empresas. Alternativamente, as empresas são multadas de acordo com o volume de GEE emitido acima do estipulado.

Outra ação europeia foi a criação de um consórcio de 48 empresas e instituições, incluindo indústrias, empresas de energia, institutos de pesquisa e universidades (Ultra-Low $\mathrm{CO}_{2}$ Steelmaking), para a cooperação em pesquisa, desenvolvimento e produção de informações relacionadas à busca por novas matérias primas, tecnologias e técnicas que impliquem em menores emissões de GEE.

Indústria cimenteira. A indústria cimenteira é caracterizada pelo intenso consumo de energia em seu processo produtivo, gerando temperaturas superiores a $1400^{\circ} \mathrm{C}$ para a produção do cimento (Soares, 1998). A indústria global de cimento vem desenvolvendo, de forma voluntária, estratégias abrangentes para a redução das emissões por meio do aumento da eficiência, substituição de combustíveis, substituição de materiais e pesquisas a respeito de processos de fabricação e aplicações de cimento e concreto. De acordo com Moradhassel e Masterson (2009), o estado canadense da Colúmbia Britânica foi a primeira localidade do mundo a impor preços elevados de carbono nas atividades de fabricação de 
cimento, com o objetivo de gerar incentivos à redução das emissões de GEE. As primeiras leis que levaram à criação dessas políticas são decorrentes um acordo internacional baseado em aumentos de eficiência energética, substituição de matérias primas e de fontes energéticas por alternativas renováveis, substituição de materiais cimentícios suplementares por materiais que emitem menos GEE, como o clínquer, e em pesquisas de longo prazo com o objetivo de buscar processos produtivos menos poluentes e menos energeticamente demandantes.

Buscando cumprir com esse acordo, desde 2008 a política de taxação de carbono (baseada na taxação diferenciada de produtos) está em vigor e consiste em uma taxa de aumento progressivo sobre a compra de combustíveis fósseis, atrelada às emissões de GEE de cada tipo de combustível e variando entre USD10 (dez dólares americanos) e USD30 por tonelada de $\mathrm{CO}_{2}$ ou equivalente emitido (Moradhassel e Masterson, 2009). Tendo em vista a conciliação de políticas de mitigação das emissões com a manutenção financeira das cimenteiras, foram sugeridas ações complementares à política existente, como o estabelecimento de um limite máximo para o valor das taxas que poderiam ser cobradas das indústrias, fixado em termos percentuais das vendas, lucros ou custos energéticos. Outra opção consistiria na cobrança de taxas pelo consumo de cimento, e não sobre a produção. Dessa forma, mesmo que com um menor potencial de redução das emissões, ficaria isenta a produção voltada para a exportação, mantendo a competitividade de mercado, ao mesmo tempo em que seria gerado um incentivo para a redução do consumo e dos custos produtivos.

\section{O Plano de Energia e Mudanças Climáticas de Minas Gerais}

O PEMC-MG é uma importante ferramenta de planejamento e gestão transversal, que abrange todos os setores socioeconômicos que tenham impacto sobre as emissões de GEE e/ou que sofram os efeitos das mudanças climáticas. Nele é apresentado um diagnóstico a partir dos dados referentes às emissões, assim como diretrizes para atuação e propostas de ações a serem tomadas para buscar a mitigação dessas emissões. 0 plano foi publicado em 2015, com informações referentes ao ano de 2010. Apesar de o PEMC-MG abordar propostas de ações para todos os setores, a seguir serão apresentadas iniciativas relacionadas aos subsetores em análise, com o propósito de contextualizar as políticas já existentes no Estado e assim sugerir, de forma mais assertiva, ações adicionais ou complementares, com base nas experiências estudadas.

\section{Subsetor "agricultura"}

Cinco políticas foram sugeridas pelo PEMC-MG para o subsetor agrícola. A primeira delas consiste na promoção da agricultura irrigada em Minas Gerais, abrangendo as áreas de sequeiro e pastagens degradadas, com o objetivo de reduzir as emissões do subsetor via crescimento de biomassa. Entretanto, há, nesse caso, um trade-off em relação à disponibilidade hídrica no Estado, que se vê criticamente restringida nos últimos anos, o que torna limitado o potencial da agricultura irrigada como forma de mitigação das emissões de GEE. Incentivos à agroecologia e à produção orgânica, visando reduzir as emissões provenientes do uso de fertilizantes e adubos químicos, constituem outra política aplicável à agricultura. Para tanto, prevê-se a promoção de ações que 
incentivem a conversão gradativa de agricultores convencionais em agroecológicos, com a ampliação dos processos de identificação e certificação dos produtores. Outra ação seria o pagamento por serviços ambientais a proprietários ou posseiros que desenvolvam práticas sustentáveis ou que mantenham áreas de florestas em suas propriedades. O PEMC-MG procura, também, apoiar e incentivar a produção e o uso sustentável de florestas plantadas por meio da estruturação das cadeias produtivas e da diversificação de produtos, da promoção do georreferenciamento florestal econômico, social e ambiental, e da elaboração de uma política florestal assertiva, que garanta a sustentabilidade ambiental da gestão das florestas plantadas. Por fim, o plano sugere a elaboração de medidas para a redução das perdas de produtos agrícolas por falhas na produção, transporte, armazenamento e abastecimento dos produtores.

\section{Subsetor "pecuária"}

A principal política indicada pelo plano ao subsetor pecuário tem como objetivo o melhoramento genético e redução das emissões de metano dos ruminantes por meio do aumento da produtividade de cada bovino, que pode ocorrer pelo aumento da produção de carne a partir de animais de maior porte ou pelo abatimento mais precoce. Para tanto, são propostas ações para estimular a realização de feiras e leilões de reprodutores bovinos que já tenham sido melhorados geneticamente e a adoção do uso em larga escala de tais reprodutores geneticamente melhorados, ampliando a transferência genética desses animais para os rebanhos de gado de corte e de leite.

\section{Subsetor "transporte"}

A primeira ação proposta pelo PEMC-MG para o subsetor transportes é a realização de um estudo de viabilidade econômica e ambiental para implantação de ciclovias nas marginais das rodovias estaduais. A segunda ação consiste na análise de incentivos à renovação da frota de caminhões, contribuindo para a criação de um banco de dados para subsidiar o processo decisório a respeito da criação de uma linha de crédito bancário para aquisição de caminhões e ônibus novos e mais eficientes. Outra ação consiste na elaboração de um diagnóstico acerca do transporte de cargas no Estado, reunindo informações como fluxos de carga, volumes transportados por distância percorrida e consumo de combustível. Essa análise visa também estudar a viabilidade da implantação de hidrovias, com o mapeamento de bacias hidrográficas navegáveis. Compras públicas de baixo carbono no setor de transportes compõem a outra ação sugerida pelo plano, previstas a partir da inserção de critérios técnicos nos editais de licitação do Estado, de maneira a promover compras de veículos mais eficientes e que permitam o uso de combustíveis com menor fator de emissão de GEE. Da mesma forma, constam no plano estudos relacionados a incentivos econômicos para aquisição de veículos híbridos e elétricos pelo setor privado. Destaca-se também a criação de um termo de referência para elaboração de estudos de impacto ambiental para contabilizar as emissões de GEE no licenciamento ambiental de obras de infraestrutura de transporte. Por fim, uma última ação seria aperfeiçoar a identificação do grau da poluição gerada pelo tráfego nas áreas urbanas, de forma a permitir a avaliação da efetividade das regras de gestão e controle da emissão de poluentes e do planejamento adequado em termos de mobilidade urbana.

\section{Subsetor "indústria"}

A primeira ação prevista no PEMC-MG direcionada ao subsetor industrial é a criação de programas relacionados à eficiência energética, com a participação do governo, empresas, indústrias e universidades. 0 objetivo é 
reduzir as perdas energéticas e apoiar a transição para uma economia de baixo carbono através da disseminação de boas práticas entre esses agentes, disponibilizando também linhas de financiamento e outros subsídios como a diferenciação tributária para equipamentos e tecnologias de baixo carbono. Outra ação consiste na criação de um "Programa de Incentivos para a Produção de Bioquerosene para Aviação e Etanol de Segunda Geração" nas refinarias já existentes no Estado. Para tanto, são sugeridos incentivos fiscais, creditícios e tratamento tributário diferenciado, como a redução do Imposto sobre a Circulação de Mercadorias e Serviços (ICMS), a fim de atrair empreendedores para o Estado. Propõese também, por meio de cooperação técnica e benefícios governamentais, o fomento à cogeração industrial processo de produção que reduz a necessidade de energia térmica pela combinação da geração de calor e de energia elétrica -, à substituição gradual de fontes energéticas com alto fator de emissão, dando preferência às fontes cujo ciclo de produção garanta o efetivo sequestro de carbono, e à análise simbiótica nos fluxos envolvidos no processo industrial, de forma a identificar oportunidades acerca da utilização de resíduos industriais como insumos para outras atividades econômicas.

\section{Análise das políticas selecionadas}

Diante da teoria e das experiências internacionais apresentadas, parte-se para a análise da aplicabilidade dessas políticas em Minas Gerais, destacando-se aquelas que não foram contempladas pelo PEMC-MG. Foram levados em consideração fatores econômicos, políticos e culturais, assim como a capacidade de financiamento estatal e a distribuição dos impactos.

Entretanto, antes disso, fazem-se necessárias algumas considerações que perpassam todas as políticas estudadas.
Primeiramente, ressalta-se que a eficiência das políticas analisadas é dada em termos do equilíbrio entre os custos das reduções das emissões e o bem-estar social. A imposição de altos custos, embora seja possível, não é desejável socialmente e acaba por inviabilizar a política. 0 que se busca é a internalização dos custos da poluição nos cálculos dos agentes econômicos no momento em que tomam as decisões produtivas. Assim, é importante que sejam delimitadas taxas para as emissões que igualem ganhos marginais em bem-estar social com os custos marginais de redução dessas emissões. Dessa forma, a eficiência estaria diretamente relacionada não apenas à política adotada, mas à forma com a qual a mesma é executada, incluindo os valores específicos de padrões, taxas e subsídios.

Em relação aos subsídios como instrumentos de mercado, é importante ressaltar que estes devem possuir caráter excepcional, para que se mantenham como instrumentos de indução de comportamento. A partir do momento em que tornam uma regra, os agentes econômicos passam a incluí-lo em seus cálculos, fazendo com que esse perca sua força incentivadora. Ainda, é importante que os incentivos concedidos passem por constantes avaliações, uma vez que, ao fornecer subsídios a certo produto, a demanda gerada pela redução de preço resulta em novas escalas e tecnologias produtivas, o que por sua vez reduz os custos produtivos. 0 custo de produção compõe o cálculo do valor do subsídio para que se atinja o máximo bem-estar social e, portanto, deve ser monitorado de forma permanente.

Outro ponto de atenção se refere às atividades cujas características intrínsecas dificultam a aplicação de instrumentos de mercado na concepção de políticas de mitigação de emissões. É o caso de setores produtivos de commodities (bens primários de qualidades uniformes e, portanto, indiferenciáveis pela sua origem), voltados para exportação, com preço 
definido pelo mercado internacional e em geral constituindo o sustentáculo da economia do país em questão, o que as coloca como foco da ação política. Ocorre, nesses casos, um desincentivo à taxação ambiental decorrente da dinâmica do mercado internacional. Ao se taxar tais setores, aumentam os custos de produção e, por conseguinte, o preço final do produto local, tornando as empresas menos competitivas e gerando um desinteresse produtivo, podendo inclusive ocasionar a evasão da produção para outras localidades com legislações ambientais mais favoráveis.

Finalmente, há que se diferenciarem instrumentos de taxação sobre o consumo e sobre a produção. A taxação sobre o consumo é uma forma de desincentivo à compra de certo bem. Contudo, o caráter localizado das políticas, válidas apenas em um determinado território, não garante a redução das emissões provenientes do processo produtivo, pois o consumo em outras localidades não sofre alteração. Assim, essa ferramenta tem efeitos limitados quando restrita a uma localidade, com efeitos prejudiciais exclusivos da população taxada. Isso ocorre porque o consumo é local, ou seja, há menos mobilidade. Por outro lado, a produção pode ser deslocada. A taxação sobre a produção atinge diretamente o fato gerador, concentrando os custos e gerando um incentivo muito grande à adesão de comportamentos desejáveis, como ações de controle da poluição. Porém, essa taxação leva à já mencionada redução da competitividade internacional das empresas locais, fazendo com que seus representantes façam grandes pressões contrárias às políticas de mitigação de emissões.

\section{Subsetor "agricultura"}

A vinculação, proposta para a União Europeia, da utilização de insumos agrícolas e sementes que resultem em menores emissões de GEE à concessão de financiamentos poderia ser aplicada em Minas Gerais, haja vista que o estado já é o maior financiador das atividades agrícolas, cuja subvenção é essencial para a manutenção dessas atividades. 0 governo estadual poderia utilizar seus bancos estatais para promover políticas de mitigação de emissões por meio da inclusão de diferentes pré-requisitos para a concessão desses financiamentos. Tal iniciativa poderia ser implementada na forma de contrapartidas, com a devida observação das capacidades dos produtores e da disponibilidade de produtos de baixo carbono no mercado. Outro ponto positivo seria a ausência de novos custos para os cofres públicos, uma vez que esses empréstimos já são realidade e estão previstos no orçamento.

Há também a possibilidade da adoção de políticas baseadas em subsídios diretos a fertilizantes, pesticidas e sementes que levem a uma menor emissão de GEE, tal como ocorre na Indonésia. A aplicação dessa política em Minas Gerais traria benefícios como a ausência de custos produtivos adicionais, que teriam que ser compensados por um elevado aporte de recursos públicos dada a escala da produção agrícola no Estado.

\section{Subsetor "pecuária"}

0 caso do Sul Asiático alude à necessidade de se aprimorar a qualidade dos alimentos dos bovinos para facilitar o processo digestivo, de forma a reduzir as emissões provenientes $\mathrm{da}$ fermentação entérica do gado. A pecuária extensiva praticada em Minas Gerais, na qual a alimentação do gado é composta basicamente por pastagens, torna difícil aplicar no Estado políticas dessa natureza. A imposição da utilização de determinado tipo de ração resultaria em grandes custos para os pecuaristas, especialmente para os pequenos produtores, e subsídios que tornem menores os preços da ração seriam demasiadamente onerosos aos cofres públicos, que teriam que arcar com a diferença entre os custos da utilização das pastagens e da ração. 
Outra sugestão, a melhora do manejo do gado por meio do aprimoramento das técnicas de reprodução e saúde dos bovinos, poderia contar com instrumentos de educação e informação por iniciativa do Estado, a serem incorporados às ações dos diversos programas estaduais de assistência técnica e extensão rural. Entretanto, instrumentos de comando e controle estariam restritos às questões de saúde pública, com o sucesso da política dependendo em maior grau de ações voluntárias por parte dos produtores e da existência de crédito para investimentos na modernização das técnicas de manejo do rebanho. Ressaltase, finalmente, que há tecnologias de baixo custo disponíveis para uma bovinocultura de maior qualidade, sendo nesse sentido que instrumentos de educação e informação poderiam maximizar os resultados em termos de produtividade e redução relativa das emissões de GEE.

\section{Subsetor "transporte"}

As primeiras políticas de mitigação das emissões de GEE apresentadas para este subsetor se relacionam à reformulação do planejamento urbano, incluindo a desconcentração dos centros comerciais, a construção de ciclovias e a maior interligação entre modais. A competência municipal de tais atribuições limita a ação em nível estadual à sua articulação com as prefeituras, buscando instrumentos de incentivo em seus planos diretores.

Em relação ao transporte privado, a experiência dinamarquesa enfatiza a taxação do consumo. Dos três instrumentos usados na Dinamarca - a tributação progressiva sobre o registro do veículo, a taxa verde sobre propriedade e o imposto sobre $o$ combustível -, o primeiro e o terceiro seriam mais facilmente conduzidos pelo governo estadual mineiro. No primeiro caso, essa constatação se deve à competência estadual da matéria e à sua maior aceitação social, uma vez que não seria necessária a criação de um novo imposto, mas apenas uma reformulação do atual Imposto sobre a Propriedade de Veículos Automotores (IPVA) que o condicione às emissões relativas de cada modelo de veículo. Sob a perspectiva da indústria automotiva, essa política não representaria necessariamente uma desvantagem em termos mercadológicos, dado que apenas alguns modelos teriam seus preços significativamente elevados. 0 que ocorreria, na prática, seria a redefinição das alíquotas, que hoje são universais, de maneira a diferenciá-las, de acordo com a eficiência do consumo de combustível do veículo. Já no segundo caso, a taxação da propriedade veicular veria sua aplicação no Estado dificultada tanto pela competência municipal na matéria, com cada localidade sujeita à captura regulatória de forma individualizada, quanto pela rejeição social que poderia advir de uma taxa adicional sobre o consumo. No terceiro caso, a taxação de combustíveis já é uma realidade via ICMS, restando refletir nos cálculos os custos das externalidades resultantes das emissões a partir desses combustíveis, tal como sugerido para o IPVA. Além da racionalização do uso de combustível, essa iniciativa poderia levar à preferência por tipos de combustível com menor impacto emissor, como o etanol, por meio da taxação diferenciada por produto.

\section{Subsetor "indústria"}

Indústria siderúrgica. As políticas chinesas de padronização do uso de energia industrial, apesar de seus resultados promissores, são caracterizadas por decisões autoritárias e unilaterais que não se observam em estados democráticos de direito como o Brasil. As relações entre estado e mercado na cultura brasileira são marcadas por negociações, tal como previsto na Teoria Econômica da Regulação, nas quais a imposição de padrões tecnológicos e produtivos à indústria têm poucas chances de sucesso. 
Por outro lado, políticas como o esquema de comércio de emissões da União Europeia seriam mais adaptáveis à realidade mineira, o que se deve à existência de um número suficiente de indústrias siderúrgicas no Estado (para que se tenha oferta e procura por créditos de carbono), à existência de tecnologias disponíveis para a promoção da redução das emissões, à existência do relatório de emissões feitas pelas próprias empresas, aos baixos custos de implantação por parte do governo e à competência, em nível estadual, para a criação de leis que prevejam o uso de instrumentos de mercado e de comando e controle. A resistência a esse modelo de política por parte das empresas siderúrgicas está diretamente relacionada ao impacto da regulação e, assim, seria indicado que a formulação da politica fosse pautada por processos participativos, nos quais técnicos reguladores estipulam as cotas de emissões e os percentuais de redução juntamente com os técnicos regulados, de forma a delimitar quantidades factíveis a custos aceitáveis, promovendo uma transição progressiva à produção de baixo carbono. Nesse caso, é importante garantir a idoneidade e qualificação dos técnicos públicos, uma vez que a assimetria de informação acerca das emissões dos processos industriais entre empresa e estado, juntamente com a possibilidade de captura dos servidores, poderiam resultar na estipulação de limites acima dos montantes socialmente desejáveis.

Indústria Cimenteira. As políticas de taxação de carbono vigentes na Colúmbia Britânica poderiam ser aplicadas em Minas Gerais, com o aproveitamento de insumos produtivos substitutos, menos poluentes e já disponíveis. Contudo, alguns fatores devem ser repensados antes da implantação de tal política, de maneira a reduzir a possível oposição feita por outros setores que utilizam esses mesmos insumos e assim manter certa equidade na distribuição desses custos adicionais. Ao se taxar de maneira diferenciada produtos que em sua queima emitem mais GEE, e dada a ilegalidade da discriminação setorial de preços, podem-se prejudicar de forma desproporcional outras atividades que não apresentem a possibilidade de substituição da fonte combustível. A definição de uma alíquota maior para o diesel, por exemplo, poderia ocasionar graves danos a atividades dependentes do uso de tratores. Os valores das taxas devem, sobretudo, resguardar os pequenos produtores de ônus abusivos, visto que estes, na maioria das vezes, apresentam menor poder de barganha em suas compras e contam com tecnologias menos eficientes. Com o objetivo de sanar tais problemas de equidade, sugere-se a complementação dessa política com instrumentos de comando e controle, impondo um limite máximo a ser cobrado de cada indústria. Essa medida garante que os diversos setores sejam taxados de forma equivalente, diminuindo a rejeição da política. No caso da indústria cimenteira em Minas Gerais, o objetivo seria, por meio de incentivos econômicos, substituir o uso de combustíveis fósseis por carvão vegetal oriundo de florestas plantadas como insumo do processo produtivo, sempre que possível.

Por fim, vale lembrar que políticas adaptadas de outros setores, como os créditos de carbono da siderurgia, não são indicadas para a indústria cimenteira, pois podem gerar problemas específicos de competitividade, tendo em vista as baixas margens de lucro do segmento. Países como os Estados Unidos, a União Europeia e Austrália classificam o setor como comercialmente vulnerável, justificando sua isenção em relação a políticas de mitigação de emissões e assim evitando a fuga de capitais do setor (Moradhassel e Masterson, 2009). 


\section{Considerações finais}

As mudanças climáticas resultantes do aumento da concentração dos GEE oriundos da ação antrópica na atmosfera constituem um problema de ordem pública e, por isso, cabe ao poder público agir de maneira a mitigá-lo ou solucioná-lo. Contudo, o desafio de reduzir o montante de emissões está condicionado à manutenção de atividades econômicas essenciais ao bem-estar social. A própria natureza do objeto a ser controlado dificulta a missão, pois se trata de gases resultantes de processos de difícil quantificação, identificação, contenção e responsabilização. Essas características em conjunto fazem com que as emissões de GEE se enquadrem no que se conceitua como externalidade. Assim, a promoção de políticas públicas, baseada em instrumentos regulatórios, tem como objetivo quantificar e internalizar os custos advindos das emissões, não contabilizados no processo de decisão dos agentes emissores. A valoração dessas externalidades implica em novos custos, gerando um alto índice de rejeição por parte dos emissores e a tentativa de influenciar e moldar políticas regulatórias a seu favor.

Nesse contexto se inserem os estudos das teorias da regulação e dos seus instrumentos regulatórios, com seus respectivos alcances e limites, na tentativa de elaborar políticas aplicáveis a um dado setor em uma dada localidade. Os resultados dessas políticas dependem de fatores econômicos, culturais, sociais, produtivos, geográficos, legais e políticos e, por isso, resulta complexa a transposição de experiências de sucesso. Apesar disso, é possível utilizá-las como ponto de partida, desde que satisfeitas certas condições, restando adaptar os mecanismos de atuação à realidade do local alvo da política. Ainda, além do desenho da política, é necessário passar pela arena política, na qual surgem conflitos de interesse e a consequente captura regulatória.
Outros trade-offs puderam ser detectados ao longo do trabalho, em adição ao já aludido equilíbrio entre a atividade econômica e a sustentabilidade ambiental, que idealmente coincidiria com a maximização do bem-estar social. Foram exemplificadas as vantagens e desvantagens, específicas para cada aplicação, de instrumentos de mercado e de comando e controle, assim como da distribuição dos custos entre os agentes e do recurso aos cofres públicos para a internalização dos mesmos. Em todo caso, diante das possibilidades de atuação, em termos do leque de modelos regulatórios e de tecnologias aplicáveis, foi possível notar um distanciamento entre o potencial de ação e os resultados práticos. Por mais que já existam inúmeros meios para atingir alguns dos objetivos de mitigação das emissões, poucos são efetivamente implementados. As dificuldades parecem estar relacionadas, em muitos casos, aos conflitos entre pressões externas para a redução de emissões e a ênfase local nos objetivos econômicos de curto prazo.

Com a análise teórica das experiências internacionais, foi possível extrair algumas constatações acerca do PEMC-MG. O plano mineiro sugere, de forma abrangente, práticas, ações e a utilização de tecnologias de ponta no combate ao aumento das emissões de GEE no Estado de Minas Gerais. Contudo, a maioria das ações previstas no PEMCMG consiste na proposição de técnicas, sem sugestões quanto à sua operacionalização. Tal fato, somado ao pouco apoio político recebido pelo PEMC-MG, dificulta a transformação dessas tecnologias em políticas públicas, restando a maior parte dessas ações ainda sem implementação na forma de políticas públicas.

A aplicabilidade das experiências de sucesso selecionadas ao Estado de Minas Gerais se mostrou promissora, em que se pesem restrições como a cultura e as finanças públicas do Estado. Para o subsetor agrícola, destaca-se a adição de critérios ambientais como requisitos 
para a concessão de financiamentos à produção; para o subsetor pecuário, instrumentos de educação e informação relacionados ao correto manejo do rebanho apresentam grande potencial; no subsetor de transportes, sobressaem possíveis resultados a partir de ferramentas tributárias já disponíveis no Estado, como o ICMS e IPVA, sendo necessária apenas sua reformulação, com base na taxação progressiva da ineficiência dos veículos; e, finalmente, no subsetor industrial, vislumbra-se a aplicação de taxas ambientais customizadas, com incentivos à formação de esquemas de comércio de emissões e, quando necessário, complementadas por padrões que visam manter certa economicidade e equidade na distribuição dos custos. Ademais, para todos os subsetores analisados, pode-se concluir que o modo de execução da política, principalmente a composição do cálculo dos valores de taxas e subsídios, é tão importante quanto a própria escolha do tipo de política, determinando seu sucesso ou fracasso.

\section{Declaração de conflitos de interesse}

Os autores declaram não haver conflitos de interesse.

\section{Referências}

Azevedo, A.; Alencar, A.; Moutinho, P.; Ribeiro, V.; Reis, T.; Stabile, M.; Guimarães, A. Panorama sobre o desmatamento na Amazônia em 2016. Nota Técnica do Instituto de Pesquisa Ambiental da Amazônia, 2016. Disponível em: <http://www.observatorio florestal.org.br/sites/default/files/panorama -desmatamento-amazonia-2016.pdf>. Acesso em: 27 abr. 2017.

Brasil. Lei no 12.187, de 29 de dezembro de 2009. Institui a Política Nacional sobre Mudança do Clima - PNMC e dá outras providências. Disponível em: <http://www.planalto.gov.br/ccivil_03/_ato 2007-2010/2009/lei/l12187.htm>. Acesso em: 12 nov. 2016.
Comissão Mista Permanente sobre Mudanças Climáticas. Legislação brasileira sobre mudanças climáticas. Congresso Nacional, $2013 . \quad$ Disponível em: <http://www.senado.leg.br/comissoes/CMM C/Livro_legislacao_ambiental_Completo_Fina 1_17_09_2013.pdf >. Acesso em: 14 nov. 2016.

Campos, H. A. Falhas de mercado e falhas de governo: uma revisão da literatura sobre regulação econômica. Prismas, v. 2, n. 8, p. 341-370, 2008.

Carvalho, P. S. L.; Mesquita, P. P. D.; Araújo, E. D. G. Sustentabilidade da siderurgia brasileira: eficiência energética, emissões e competitividade. BNDES Setorial, v. 41, p. 181-236, 2015.

FEAM - Fundação Estadual do Meio Ambiente. Estimativas de emissões e remoções de gases de efeito estufa do Estado de Minas Gerais - ano base 2010. 2013. Disponível em: <http://www.feam.br/ images/stories/arquivos/mudnacaclimatica/ 2013/estimativas_gee_2010_231213.pdf>.

Acesso em: 24 nov. 2016.

FEAM - Fundação Estadual do Meio Ambiente. Plano de energia e mudanças climáticas de Minas Gerais (sumário executivo). 2015. Disponível em: <http://www.feam.br/images/stories/2015 /ENERGIA_M_CILMATICAS/010615pemc_su mario_executivo_capa_nova_ficha_catalografi ca.pdf $>$. Acesso em: 19 nov. 2016.

FEAM - Fundação Estadual do Meio Ambiente; Centro Clima - Universidade Federal do Rio de Janeiro. Inventário de emissões de gases de efeito estufa do Estado de Minas Gerais. 2008. Disponível em: <http://www.feam.br/images/stories/inven tario/inventario_de_emissoes_de_gases_-

_feam_versao_para_internet.pdf $>$. Acesso em: 24 nov. 2016.

Fundação João Pinheiro. Produto interno bruto de Minas Gerais. 2010 (relatório anual). 2012. Disponível em: <http://www.fjp.mg.gov.br/index.php/docm an/cei/pib/pib-anuais/135-informativo-ceipib-mg-2010/file>. Acesso em: 10 jun. 2017.

Gattinger, A.; Jawtusch, J.; Muller, A. Mitigating greenhouse gases in agriculture: a challenge and opportunity for agricultural policies. Diakonisches Werk der Evangelischen Kirche in Deutschland, 2011. Disponível em: <http://infoagronet/ programas/Ambiente/pages/mitigacion/doc umentos/5.pdf>. Acesso em: 09 jul. 2017. 
Gerber, P. J.; Steinfeld, H.; Henderson, B.; Mottet, A.; Opio, C.; Dijkman, J.; Falcucci, A.; Tempio, G. Tackling climate change through livestock: A global assessment of emissions and mitigation opportunities. Roma: FAO, 2013. Disponível em: <http://www.fao.org/3/i3437e.pdf>. Acesso em: 02 maio 2017.

INPE - Instituto Nacional de Pesquisas Espaciais. Quais as consequências do aquecimento global? 2011. Disponível em: <http://www.inpe.br/acessoainformacao/no de/483>. Acesso em: 01 jun. 2017.

Lowi, T. J. American business, public policy, case-studies, and political theory. World Politics, v. 16, n. 4, p. 677-715, 1964.

Lowi, T. J. Four systems of policy, politics, and choice. Public Administration Review, v. 32, n. 4, p. 298-310, 1972. https://doi.org/ $10.2307 / 974990$

Margulis, S. A regulamentação ambiental: instrumentos e implementação. Rio de Janeiro: IPEA, 1996. (Texto para discussão, 437). Disponível em: <http://www.ipea.gov.br/agencia/images/st ories/PDFs/TDs/td_0437.pdf>. Acesso em: 29 nov. 2016.

Mathiesen, B.; Kappel, J. Transport policies related to climate change mitigation: The case of Denmark. Aalborg: Department of Development and Planning, Aalborg University, 2013. Disponível em: <http://www.regeringen.se/4a4b1c/content assets/7bb237f0adf546daa36aaf0 $44922 f 47$

3/underlagsrapport-6---danmark.pdf>.

Acesso em: 02 dez. 2016.

Minas Gerais. Decreto no 43.372, de 05 de junho de 2003. Cria o Núcleo de Gestão Ambiental - NGA nas Secretarias de Estado que menciona e dá outras providências. Disponível em: <http://www.siam.mg. gov.br/sla/download.pdf?idNorma=1929>. Acesso em: 20 nov. 2016.

Minas Gerais. Decreto no 44.042, de 09 de junho de 2005. Institui o Fórum Mineiro de Mudanças Climáticas. Disponível em: <http://www.siam.mg.gov.br/sla/download. pdf?idNorma=4767>. Acesso em 18 nov. 2016.
Minas Gerais. Decreto no 45.229, de 03 de dezembro de 2009. Regulamenta medidas do poder público do Estado de Minas Gerais referentes ao combate às mudanças climáticas e gestão de emissões de gases de efeito estufa e dá outras providências. Disponível em: <http://www.siam.mg. gov.br/sla/download.pdf?idNorma=12890>. Acesso em: 19 nov. 2016.

Minas Gerais. Decreto no 46.818, de 12 de agosto de 2015. Cria o Comitê Político do Plano de Energia e Mudanças Climáticas de Minas Gerais. Disponível em: $<$ https://www.almg.gov.br/consulte/legislac ao/completa/completa.html?tipo=DEC\&num $=46818 \& \mathrm{comp}=\& a n o=2015>$. Acesso em 19 nov. 2016.

Moradhassel, A.; Masterson, B. Advancing the cement industry's climate change plan in British Columbia: addressing economic and policy barriers. Paper presented at the Economic Implications of Climate Change Session of the 2009 Annual Conference of the Transportation Association of Canada. Vancouver: Cement Association of Canada, 18-21 October 2009.

Municipality of Copenhagen. Eco-metropole. Our vision for Copenhagen 2015. 2007. Disponível em: <http://www.bondam.dk/ files/7/miljoeudspil_brochure_engelsk.pdf>. Acesso em: 09 jun. 2017.

Posner, R.A. Theories of economic regulation. The Bell Journal of Economics and Management, v. 5, n. 2, p. 335-358, 1974. https://doi.org/10.2307/3003160

Rua, M. G.; Romanini, R. Tipologias e tipos de políticas públicas. In: Rua, M. G.; Romanini, R. (Ed.). Para aprender políticas públicas. Brasília: IGEPP, 2011. p. 48-54.

Soares, J. B. Potencial de conservação de energia e de mitigação das emissões de gases de efeito estufa para a indústria brasileira de cimento Portland até 2015. Rio de Janeiro: Universidade Federal do Rio de Janeiro, 1998. (Tese de doutorado).

World Steel Association. World steel in figures 2016. 2016.

World Trade Organization. World trade statistical review 2016. 2016. 